Nevşehir Bilim ve Teknoloji Dergisi Cilt 6(ICAFOF 2017 Özel Sayı) 226-232 2017

DOI: 10.17100/nevbiltek.334157

URL: http://dx.doi.org/10.17100/nevbiltek.334157

\title{
Un Kurdu Böceğinin Besin İçeriği ve Kanatlı Hayvan Beslemede Kullanım İmkânları
}

\author{
Süleyman ÇALIŞLAR* \\ Kahramanmaraş Sütçü Imam Üniversitesi Ziraat Fakültesi, Zootekni Bölümü, Kahramanmaraş \\ Öz
}

Kümes kanatı hayvanları, tüy gelişimi, et ve yumurta üretimi için yüksek miktarda protein, aminoasit ve enerjiye gereksinim duyarlar. Bitkisel menşeyli yemlerin amino asit içerikleri, protein kaliteleri ve mineral miktarları daha düşüktür. Bu nedenle yemlerde kullanılan mısır ve soya küspesi (SK) bazen kanatlı hayvanların besin ihtiyaçlarını karşılamada yeterli olmaz. Böyle durumlarda daha pahalı olan balık unu gibi ürünler kullanılır. Hâlbuki balık unu, maya ve malt gibi ürünlerle kıyaslanabilir düzeyde besin içeriğine sahip olan yem kaynakları mevcuttur. Un kurtları, çekirgeler, solucanlar ve karasinekler kanatlı hayvanların beslenmesinde değerlendirilebilecek kaynaklardan sadece bazılarıdır. Kanatlı hayvan rasyonlarında mısır, SK ve balık unu yerine bir yem kaynağı olarak kullanım potansiyeli olan önemli böceklerden birisi de un kurdudur. Kolay üreyen ve beslenen un kurdunun (Tenebrio molitor L.) protein, yağ, enerji, yağ asitleri bakımından zengin olduğu ve kanatlı hayvan beslemede başarıyla kullanılabileceği belirtilmektedir. Bununla birlikte $\mathrm{AB}$ mevzuatı, üretimindeki zorluklar ve üretim maliyetinin yüksek olması gibi hususlar, kanatlı hayvanların beslenmesinde un kurdunun kullanımını sınırlandırmaktadır. Bu derleme çalışmada, un kurdunun organik kanatlı hayvan beslemede kullanım imkânları incelenmiştir.

Anahtar Kelimeler: Un kurdu (Tenebrio molitor L.), Kanatlı hayvan, Alternatif yem, Organik besleme

\section{Nutrient Content of Mealworms (Tenebrio molitor L.) and The Utilization Possibilities in Poultry Nutrition}

\begin{abstract}
Poultry require high amounts of protein, amino acids and energy for feather development, meat and egg production. Herbal nutritional feeds have lower amino acid content, protein qualities and mineral levels. Therefore, corn and soybean meal used in feeds are sometimes not sufficient to meet the nutritional needs of poultry. In such cases, more expensive products like fish meal are used. However, there are feed sources that have comparable levels of nutrients to products such as fish meal, yeast and malt. Mealworms, earth worms, grasshoppers and houseflies are only some of the sources that can be evaluated for the feeding of poultry. One of the important insects with potential for use as a feed source instead of corn, soybean meal and fish meal in poultry rations is mealworm. Easy to breed and feding Tenebrio molitor L. (TM) is rich in protein, fat, energy, fatty acids and can be used successfully in poultry feeding. However, EU legislation, difficulties in production and high cost of production limit the use of mealworm in the feeding of poultry. In this review study, the utilization possibilities of mealworm in organic poultry feeding were examined.
\end{abstract}

Keywords: Mealworm (Tenebrio molitor L.), Poultry, Alternative feed, Organic feeding

*e-mail: scalislar@ksu.edu.tr 


\section{Giriş}

Kümes hayvanları, tüy gelişimi, et ve yumurta üretimi için yüksek miktarda protein, aminoasit ve enerjiye gereksinim duyarlar [1]. Bitkisel menşeyli yemlerin amino asit içerikleri, protein kaliteleri ve mineral oranları daha düşüktür. Bu nedenle yemlerde kullanılan mısır ve soya küspesi (SK) bazen kanatlı hayvanların besin ihtiyaçlarını karşılamada yeterli olmaz [2]. Böyle durumlarda daha pahalı olan balık unu gibi ürünler kullanılır. Halbuki balık unu, maya ve malt gibi ürünlerle kıyaslanabilir düzeyde besin içeriğine sahip böcekler mevcuttur [3], [4], [5]. Kanatlı hayvanların beslenmesinde bir yem kaynağı olarak böceklere duyulan ilgi her geçen gün artmaktadır [6]. Avrupa ülkelerinde yeni bir hayvan yemi kaynağı olarak böcekler kullanılmaktadır [7]. Kanatlı hayvanların beslenmesinde SK ve balık unu yerine bir yem kaynağı olarak kullanımı yaygınlaşan böceklerin başında un kurdu (UK) gelmektedir [8], [9]. Hızlı üreyen, kolay beslenen un kurtlarının yemden yararlanma oranları (1.4:1 ve 2:1) oldukça yüksektir [8], [10]. Birim kg üretim için böceklerin sera gazı ve amonyak salınımları sığırlardan daha düşüktür [11]. UK'nın (Tenebrio molitor L.) larva ve pupasının protein [12], yağ [13], enerji [14], yağ asitleri [15], [16] bakımından zengin olduğu ve kanatlı hayvan beslemede başarıyla kullanılabileceği belirtilmiştir [8]. Tenebrio molitor'un larvaları evcil hayvanların yanı sıra hayvanat bahçelerinde ve yaban hayatı parklarındaki egzotik kuşların beslenmesinde canlı olarak kullanılmaktadır [17], [18], [19]. Bununla birlikte $\mathrm{AB}$ mevzuatı engeli, üretimindeki zorluklar ve birim maliyetin yüksek olması gibi hususlar tavukların beslenmesinde UK'nın kullanımını sınırlandırmaktadır.

\section{Un Kurdu Böceğinin Genel Özellikleri ve Besin İçeriği}

Un kurdu (Tenebrio molitor L.) 280 ila 630 gün arasında değişebilen bir yaşam döngüsüne sahiptir. Yumurtadan 10-12 gün sonra (18-20 $\left.{ }^{\circ} \mathrm{C}\right)$ açığa çıkan larvalar 3-4 ay sonra (oda sıcaklığında) ergin hale gelirler. Ergin hale gelmeleri 18 ay kadar sürebilir. Larvalar 20-32 mm uzunluğunda ve 130$160 \mathrm{mg}$ ağırlığındadır. Erginler $300 \mathrm{mg}$ ağırlığa ulaşırlar [14] ve 2-3 ay kadar yaşarlar [20].

Böcekler sıcaklık değişimlerine karşı dirençli canlılardır. Böceklerin çoğu için optimum sıcaklık 20 ile $35 \mathrm{C}$ derece [21], maksimum sıcaklıklar ise $40-50^{\circ} \mathrm{C}$ arasında [22] değişmektedir.

Un kurtları sıcaklık değişimlerine dayanıklı olup $28 \mathrm{C}$ derecede optimum gelişim olurken, $15 \mathrm{C}$ derecede ancak 48 saat yaşayabilirler. Bununla birlikte \%30-55 arasında nem ihtiyaçları vardır. Nem değişimine oldukça hassastırlar. Yüksek nem (\%70 ve üzeri) koşulları altında un kurtları çok çabuk ölürler [23].

Ergin 30 adet un kurdu için 15-30 cm ebatındaki bir kap yeterli olmaktadır. Kabın tabanına 4-5 cm yüksekliğinde altlık koyulmalıdır. Un kurtlarının 90 günlük bir süre beslenmesi için 500 gram yem düşünülmelidir [8]. Kullanılan kabın plastikten yapılmış olması temizlik ve hijyen bakımından gereklidir.

Yumurtadan çıkan böceklerin larva, pupa ve ergin evreleri olup her evrede besin içerikleri farklı olmaktadır [24]. Taze UK'nın kuru madde (KM) oranı \%37.1 ile \%57.6 arasında değişmektedir [14]. UK'nın larvaları KM bazında \%47.4, pupası \%53.1 ve ergini ise \%60.2 HP içermektedir. Aynı şekilde larva \%5 ham selüloz (HS) içerirken ergindeki HS oranı \%16.3'e kadar çıkabilmektedir [8]. Diğer bir araştırmada, UK larvasının kuru maddede $\% 46.44 \mathrm{HP}, \% 32.7$ ham yağ (HY) ve $\% 4.58$ HS, ergin olanının ise \%63.34 HP, \%7.59 HY ve \%25.96 HS içerdiği belirtilmiştir [25]. 
UK böceğinin HP, ME ve yağ içeriği SK'dan daha yüksektir [26]. Hatta kurutulmuş UK, balık ununun yerini doldurabilecek yeterliliğe sahiptir [27], [28]. UK'nın enerji değeri (24.4 MJ/kg KM [5], soya fasulyesinden $\% 50$, mısırdan $\% 87$, balık, fasulye ve mercimekten $\% 70$, buğday ve çavdardan $\% 95$ daha fazladır [29]. UK'nın vitamin, mineral ve yağ asitleri içeriğinin de yüksek olduğu belirtilmiştir [30], [31].

Un kurdu böceği omnivordur ve tüm bitki çeşitleri ile et ve tüy gibi hayvansal ürünleri yiyebilmektedir [8]. Genellikle, taze meyve ve sebze (havuç, patates, marul) takviyeli olan tahıl kepeği veya unu, soya fasulyesi unu, yağsız süt tozu veya maya gibi protein kaynakları ile birlikte verilmelidir [17], [18]. Un kurdu diyetleri yaklaşı \%20 protein (KM bazında) içerecek şekilde dengelenmelidir [8]. Un kurtları beslendiği yemler içerisindeki az miktarlardaki suyu kullanabilmektedirler. Yeterince su alamayan un kurtlarının verimliliği düşük olmakta yılda sadece bir döl verebilmektedirler. Daha üretken olabilmeleri için (yılda 6 nesil) un kurduna su içeriği yüksek yemler (küflenmemiş) verilmelidir [18]. Un kurdu böceklerinin beslenmesinde genellikle canlı yemler kullanılmakla birlikte ticari olarak kurutulmuş larva yemler de mevcuttur.

Un kurdu larvaları $50{ }^{\circ} \mathrm{C}$ 'de 1-3 gün [32], [8], güneş altında 2 gün [6] ve $100{ }^{\circ} \mathrm{C}$ 'de 200 dakika [28] kurutulmak suretiyle ticari yem haline dönüş̧ürülmektedir. Taze un kurdunda su oranı \%56.27 iken kurutulmuş un kurdunda bu oran \%2.43'e kadar düşmektedir [33].

\section{Un Kurdu Böceğinin Kanatı Hayvan Beslemede Kullanım İmkanları}

Kümes kanatlı hayvanlarının beslenmesinde bir yem kaynağı olarak UK'nın kullanımına ilişkin çeşitli araştırmalar yürütülmektedir. Böceklerin kanatlı hayvanlar için potansiyel bir yem olarak kullanılmaya başlaması 1970'li yıllara dayanmaktadır. Bu kapsamda ev sinekleri [34], mormon cırcır böcekleri [14], ipek kurdu larvası [35] ve un kurdu [36], [37] kullanılmıştır.

Kanatlı rasyonlarında UK kullanımına ilişkin bilgiler sınırlıdır. Kurutulmuş UK larvaları, etlik piliçlerin [26], [5], [38] ve tavukların beslenmesinde kullanılmaktadır [39], [40]. UK, içerdiği protein kalitesi bakımından rasyonlarda SK yerine rahatlıkla ikame edilebilecek bir üründür ancak metiyonin içeriği kanatlı hayvanlar için yetersizdir [8]. Yem tüketimi, ağırlık kazancı ve yemden yararlanma oranına (YYO) olumsuz bir etkiye neden olmaksızın kurutulmuş UK'nın etlik piliç rasyonlarında \%7.5 [38] ve $\% 10$ [8] oranlarında kullanılabildiği bildirilmiştir. Büyüme üzerinde olumsuz etkisi olmaksızın temel kanatlı diyetlerine \%25 kadar UK kullanılabileceği vurgulanmıştır [41].

Balık unu yerine UK kullanılan diyetlerin kalitesinde iyileşme meydana geldiği ve tavukların yumurta veriminin \%2-4 arasında daha fazla olduğu tespit edilmiştir [28]. \%30 UK içeren diyetlerin etlik piliçlerin canlı ağılık artışına etkisi önemsiz ( $\mathrm{P}>0.05)$, yemden yararlanma oranına etkisi ise önemli $(\mathrm{P}<0.05)$ olmuştur. Kontrol grubuna göre, $\mathrm{UK}$ içeren diyetlerle beslenen piliçlerin immun sistem tepkilerinin daha yüksek olduğu tespit edilmiştir [26].

Un kurdu kanatlı hayvanlar için kaliteli bir besindir. Yüksek miktarda protein (\% 45-60 KM) ve yağ (\%30-45 KM) içerirler. Yeni larva yaklaşık \%60 su içerir. Kül miktarı \%5’ten (kuru madde bazında) daha düşüktür. Diğer böcekler gibi un kurdu böceği de kalsiyum bakımından yetersizdir. Bu nedenle tek başına un kurdu ile beslenen hayvanlarda metabolik kemik rahatsızlıkları meydana gelmektedir [32]. Bu nedenle un kurdu ile beslenen hayvanların diyetlerine kalsiyum takviyesi yapılmalıdır. Tenebrio 
molitor'un larvaları kuru madde bazında \%47.4, pupası \%53.1 ve ergini ise \%60.2 HP içermektedir. Aynı şekilde larva $\% 5$ selüloz içerirken ergindeki selüloz oranı \%16.3'e kadar çıkabilmektedir [8]. Diğer bir çalışmada, un kurdu larvasının kuru maddede \%46.44 HP, \%32.7 HY ve \%4.58 HS, ergin un kurdunun \%63.34 HP, \%7.59 HY ve \%25.96 HS içerdiği belirtilmiştir [25]. Un kurdunun enerji içeriği $5543 \mathrm{kcal}$ toplam enerji / kg [8]) ile $6490 \mathrm{kcal}$ toplam enerji $/ \mathrm{kg}$ [42] arasında değişmektedir. Un kurdu larvaları, KM bazında \%2.8 kitin içermektedir. Kanatlı hayvan beslemede bunun dikkate alınması gerekir [43].

\section{Sonuç ve Öneriler}

Organik hayvansal üretime dönüşün yaşandığı 21. yüzyılda, kanatlı hayvanların rasyonlarında geleneksel bitkisel ürünlerin yerine GDO'dan ari, doğal ürünlerin kullanılması gerekmektedir. Yüksek besin içeriğine sahip, GDO sorunu olmayan ve tamamen doğal bir ürün olan un kurdunun SK ve balık unu gibi yemlerin yerine ikame edilmesi mümkün görülmektedir. Ancak Avrupa Birliği, işlenmiş hayvansal protein ilavesi düzenlemesi ile böcek unlarının çiftlik hayvanlarının yemlerinde kullanımını engellediği için un kurdunun kanatı hayvan yemlerinde kullanılması yasal açıdan şimdilik mümkün görülmemektedir. Yakın zamanda bu engelin kalkacağı tahmin edilmektedir. Yasağın kalkmasıyla özellikle un kurdu böceğinin kanatlı beslemede kullanım potansiyelinin yüksek olacağı düşünülmektedir. Bununla birlikle bir böcek olarak un kurdunun da alerjik ve toksik etkilere neden olma ihtimali vardır. Bundan dolayı un kurdunun yetiştiriciliği, üretimindeki otomasyon, rasyonlarda kullanım düzeyi ve kanatlı hayvan beslemede kullanımına ilişkin detaylı bilimsel araştırmalara gerek vardır.

\section{Kaynaklar}

[1] Hossain, S.M., Blair R., "Chitin utilisation by broilers and its effect on body composition and blood metabolites” British Poultry Science, 48:33-38, 2007

[2] Ravindran V., Blair, R., "Feed resources for poultry production in Asia and the Pacific" World's Poultry Science Journal, 49:219-235, 1993

[3] Makkar, H.P.S., Tran, G., Heuze, V., Ankers, P., "State of the art on use of insects as animal feed”. Animal Feed Science and Technology, 197,1-33, 2014

[4] Van Broekhoven, S., Oonincx, D.G., van Huis A., van Loon, J.J., "Growth performance and feed conversion efficiency of three edible mealworm species (Coleoptera: Tenebrionidae) on diets composed of organic by-products” Journal of Insect Physiology, 73(0):1-10, 2015

[5] De Marco, M., Martinez, S., Hernandez, F., Madrid, J., Gai, F., Rotolo, L., Belforti, M., Bergero, D., Katz, H., Dabbou, S., Kovitvadhi, A., Zoccarato, I., Gasco, L., Schiavone, A, "Nutritional value of two insect meals (Tenebrio molitor and Hermetia illucens) for broiler chickens: apparent nutrient digestibility, apparent ileal amino acid digestibility and apparent metabolizable energy” Animal Feed Science and Technology, 209: 211-218, 2015

[6] Ng, W.K., Liew, F.L., Ang, L.P., Wong, K.W., "Potential of mealworm (Tenebrio molitor) as an alternative protein source in practical diets for African catfish, Clarias gariepinus" Aquaculture Research, 32 (Supplement 1): 273-280, 2001

[7] Van Huis, A., "Potential of insects as food and feed in assuring food security"Annual Reviews Entomology, 58:121-130, 2013 
[8] Ramos-Elorduy, J., Gonzalez, E.A., Hernandez, A.R., Pino, J.M., "Use of Tenebrio molitor (Coleoptera:Tenebrionidae) to recycle organic wastes and as feed for broiler chickens” Journal of Economy Entomology, 95 (1): 214-220, 2002

[9] Yi, L., Sagis, Lakemond, C.M., Eisner-Schadler, V., van Huis, A., van Boekel, M.A., "Extraction and characterisation of protein fractions from five insect" Food Chemistry, 141, pp. 3341-3348, 2013

[10] Oonincx, D.G.A.B., de Boer, I.J.M., "Environmental impact of the production of mealworms as a protein source for humans - a life cycle assessment” Plos one, pp 1-5, Volume 7, article number e51145, 2012

[11] Smith, R., Pryor, R., "Enabling the exploitation of insects as a sustainable source of protein for animal feed and human nutrition” PROteINSECT grant agreement number: 312084. Work Package 5: Pro-Insect Platform in Europe-Deliverable, 5.1. 2014

[12] Ghaly, A.E., Alkoaik, F.N., “The yellow mealworms as a novel source of protein” American Journal of Agricultural and Biological Sciences, 4 (4):319-331, 2009

[13] Yi, L., Van Boekel, M.A.J.S., Boeren, S., Lakemond, C.M.M., "Protein identification and in vitro digestion of fractions from Tenebrio molitor" European Food Research Technology, 242: 1285-1297, 2016

[14] Finke, M.D., “Complete nutrient composition of commercially raised invertebrates used as food for insectivores” Zoo Biology, 21 (3):269-285, 2002

[15] Belluco, S., Losasso, C., Maggioletti, M., Alonzi, C.C., Paoletti, M.G., Ricci, A., "Edible insects in a food safety and nutritional perspective: a critical review" Comprehensive Reviews in Food Science and Food Safety, volume 12: 296-313, 2013

[16] Dreassi, E., Cito, A., Zanfini, A., Materozzi, L., Botta, M., Francardi, V., "Dietary fatty acids influence the growth and fatty acid composition of the yellow mealworm Tenebrio molitor (Coleoptera: Tenebrionidae)” Lipids. 52(3):285-294,2017

[17] Aguilar-Miranda, E.D., López, M.G., Escamilla-Santana, C., Barba de la Rosa, A.P., "Characteristics of maize flour tortilla supplemented with ground Tenebrio molitor larvae" Journal of Agricultural and Food Chemistry, 50 (1): 192-195, 2002

[18] Hardouin, J., Mahoux, G., “Zootechnie d'insectes - Elevage et utilisation au bénéfice de l'homme et de certains animaux" Bureau pour l'Echange et la Distribution de l'Information sur le Miniélevage (BEDIM), 164 p, 2003

[19] Veldkamp, T., van Duinkerken, G., van Huis, A., Lakemond, C.M.M. Ottevanger, E., Bosch, G., van Boekel, M.A.J.S., "Insects as a sustainable feed ingredient in pig and poultry diets - a feasibility study. Rapport 638- Wageningen” Livestock Research, 2012

[20] Hill, D.S., "Pests of stored foodstuffs and their control” Kluwer Academic Publishers, 476 p, 2002.

[21] Child, R.E., "Insect Damage as a Function of Climate” In: T. Padfield and K. Borchersen, eds. Museum Microclimates, 57 p. Copenhagen: National Museum of Denmark, 2007

[22] Heinrich, B., "Ecological and evolutionary perspectives In: Heinrich, B. (Ed.), Insect Thermoregulation” Wiley, New York, pp. 236-302, 1981

[23] Jozefiak, D., Engberg, R.M., “Insect as poultry feed” 20th European symposium on Poultry Nutrition, 24-27 August, Prague, Czech Republic, 2015 
[24] Zuidhof, M.J., Molnar, C.L., Morley, F.M., Wray, T.L., Robinson, F.E., Khan, B.A., Al-Ani, L., Goonewar Dene, L.A, "Nutritive value of house fly (Musca domestica) larvae as a feed supplement for turkey poults” Animal Feed Science and Technology, 105, 225-230, 2003

[25] Ravzanaadii, N., Kim, S.H., Choi, W.H., Hong, S.J., Kim, N.J., Nutritional value of mealworm, Tenebrio molitor as food source. International Journal of Industrial Entomology, Vol. 25, No. 1, pp. 93-98, 2012

[26] Bovera, F., Piccolo, G., Gasco, L., Marono, S., Loponte, R., Vassalotti, G., Mastellone, V., Lombardi, P., Attia, Y.A., Nizza, A., "Yellow mealworms larvae (Tenebrio molitor, L.) as protein source for broilers: effects on growth performance and blood profiles" British Poultry Science, 56: 569-575, 2015

[27] DeFoliart, G., "Insect fatty acids: Similar to those of poultry and fish in their degree of unsaturation, but higher in the polyunsaturates” The Food Insects Newsletter, 4, 1-4, 1991

[28] Wang, Y., Chen, Y., Li, X., Xia, J., Du, Q., Sheng, Z., "Study on rearing the larvae of Tenebrio molitor Linne and the effects of its processing and utilization” Acta Agriculturae Universitatis Henanensis, 30 (3): 288-292, 1996

[29] DeFoliart, G., "Insects as human food" Crop Protection, 11, 395-399, 1992

[30] Banjo, A.D., Lawal, O.A., Songonuga, E.A., "The nutritional value of fourteen species of edible insects in South West Nigeria” Africa Journal Biotechnology, 5: 289-301, 2006

[31] Xiaoming, C., Ying, F., Hong, Z., Zhiyong., C. "Review of the nutritive value of edible insects" Food and Agricultural Organization of the United Nations, Regional Office for Asia and Pacific, Bangkok, 85 p, Thailand, 2010

[32] Klasing, K.C., Thacker, P., Lopez, M.A., Calvert, C.C., "Increasing the calcium content of mealworms (Tenebrio molitor) to improve their nutritional value for bone mineralization of growing chicks” Journal of Zoo and Wildlife Medicine, 31 (4): 512-517, 2000

[33] Siemianowska, E., Kosewska, A., Aljewicz, M., Skibniewska., Polak Juszczak, K.L., Jarocki, A., Jędras, M., "Larvae of mealworm (Tenebrio molitor L.) as European novel food" Agricultural Sciences, 4(6), 287-291, 2013

[34] Onifade, A.A., Oduguwa, O.O., Fanimo, A.O., Abu, A.O., Olutunde, T.O., Arije, A., Babatunde, G.M., "Effects of supplemental methionine and lysine on the nutritional value of housefly larvae meal (Musca domestica) fed to rats” Bioresource Technology, 78:191-194, 2001

[35] Rao, P.U., "Chemical composition and nutritional evaluation of spent silk worm pupae” Journal of Agricultural and Food Chemistry, 42:2201-2203,1994

[36] Hernández, M.M., “Optimización del cutlivo de Tenebrio molitor L. (Coleóptera: Tenebrionidae) en condiciones de laboratorio en relación con la cantidad de racion empleada" thesis, 76 p. Fac. Ciencias, Univ. Nal. Autón México, 1988

[37] Lagunes L.A., Garcia Vázquez, L., "Productividad obtenida de dos insectos, al reciclar de echos orgánicos de origen animal y vegetal” M.S. thesis, 353p. Fac. Ciencia Univ. Nat. Autón México, 1994

[38] Biasato, I., De Marco, M., Rotolo, L., Renna, M., Lussiana, C., Dabbou, S., Capucchio, M.T., Biasibetti, E. Costa, P., Gai, F., Pozzo, L., Dezzutto, D., Bergagna, S., Martinez, S., Gasco, L., Schiavone, A., "Effects of dietary Tenebrio molitor meal inclusion in free-range chickens" The Journal of Animal Physiology and Animal Nutrition, 100 (6): 1104-1112, 2016 
[39] Giannone, M., “A natural supplement made of insect larvae” Rivista di Avicoltura, 72 (4): 38, 40-41, 2003

[40] Wang, D., Zhai, S.W., Zhang, C.X., Bai, Y.Y., An, S.H., Xu, Y.N., "Evaluation on nutritional value of field crickets as a poultry feedstuff” Asian-Australasian Journal of Animal Sciences. 18(5): 667-670, 2005

[41] Schiavone, A., De Marco, M., Rotolo, L., Belforti, M., Martinez Mirò, S., Madrid Sanchez, J., Hernandez Ruiperez, F., Bianchi, C., Sterpone, L., Malfatto, V., Katz, H., Zoccarato, I., Gai, F., Gasco, L., "Nutrient digestibility of Hermetia illucens and Tenebrio molitor meal in broiler chickens” Abstract book Conference “Insects to Feed The World”, The Netherlands 14-17 May 2014, pp. 84, 2014

[42] Bernard, J.B., Allen, M.E., Ullrey, D.E., "Feeding captive insectivorous animals: Nutritional aspects of insects as food” Nutrition Advisory Group Handbook. Fact Sheet 003, August: 1-7, 1997

[43] Finke, M.D., “Complete nutrient content of four species of feeder insects” Zoo Biology, 32:2736, 2012 